\title{
Isolate Virulence and Cultivar Response in the Winter Wheat: Pyrenophora tritici-repentis (Tan Spot) Pathosystem in Oklahoma
}

\author{
Kazi A. Kader ${ }^{1}$, Robert M. Hunger ${ }^{1 *}$, and Mark E. Payton ${ }^{2}$ \\ ${ }^{I}$ Department of Entomology and Plant Pathology, Oklahoma State University, Stillwater, OK 74078, USA \\ ${ }^{2}$ Department of Statistics, Oklahoma State University, Stillwater, OK 74078, USA
}

(Received on February 2, 2021; Revised on May 25, 2021; Accepted on May 31, 2021)

Prevalence of tan spot of wheat caused by the fungus Pyrenophora tritici-repentis has become more prevalent in Oklahoma as no-till cultivation in wheat has increased. Hence, developing wheat varieties resistant to tan spot has been emphasized, and selecting pathogen isolates to screen for resistance to this disease is critical. Twelve isolates of $\boldsymbol{P}$. tritici-repentis were used to inoculate 11 wheat cultivars in a greenhouse study in splitplot experiments. Virulence of isolates and cultivar resistance were measured in percent leaf area infection for all possible isolate $\mathrm{x}$ cultivar interactions. Isolates differed significantly $(P<0.01)$ in virulence on wheat cultivars, and cultivars differed significantly in disease reaction to isolates. Increased virulence of isolates detected increased variability in cultivar response (percent leaf area infection) $(r=0.56, P<0.05)$ while increased susceptibility in cultivars detected increased variance in virulence of the isolates $(r=0.76, P<0.01)$. A significant isolate $\times$ cultivar interaction indicated specificity between isolates and cultivars, however, cluster analysis indicated low to moderate physiological specialization. Similarity in wheat cultivars in response to pathogen isolates also was determined by cluster analysis. The use of diverse isolates of the fungus would facilitate evaluation of resistance in wheat cultivars to tan spot.

*Corresponding author.

Phone) +1-405-744-9958, FAX) +1-405-744-6039

E-mail) bob.hunger@okstate.edu

Handling Editor : Junhyun Jeon

(c) This is an Open Access article distributed under the terms of the Creative Commons Attribution Non-Commercial License (http:// creativecommons.org/licenses/by-nc/4.0) which permits unrestricted noncommercial use, distribution, and reproduction in any medium, provided the original work is properly cited.

Articles can be freely viewed online at www.ppjonline.org.
Keywords : cultivar response, isolate virulence tan spot, wheat

The ascomycete fungus Pyrenophora tritici-repentis (Died.) Drechs. (anamorph Drechslera tritici-repentis (Died.) Shoemaker) is the pathogen of tan spot of wheat. To complete its life cycle, this pathogen survives and overwinters on plant residue left in the field (Bockus et al., 2010; Francl et al., 1992; Odvody et al., 1982). The fungus forms sexual fruiting bodies (pseudothecia) on wheat residue from which the primary inoculum, ascospores, are ejected to initiate tan spot in a favorable environment (Shabeer and Bockus, 1988). Thus, wheat residue on which the fungus completes its life cycle provides initial inoculum of $P$. tritici-repentis, which increases tan spot incidence and severity in a favorable environment. In the central plains of the United States, yield losses in wheat due to tan spot may range from $3 \%$ to 50\% (Ali and Francl, 2003). A 40\% yield loss in wheat due to tan spot was reported in Kansas (Sone et al., 1994). Depending on the fungal isolates used, Kader (2010) reported $7.3 \%$ to $25.2 \%$ yield loss in wheat due to tan spot in Oklahoma. Hence, tan spot is a significant problem to wheat cultivation in Oklahoma where no-till practices, which leaves greater amounts of wheat residue in the field (Hunger and Brown, 1987), are being increasingly adopted.

The use of host resistance is the best option in disease management. Using partial resistance, Singh et al. (2008) reported a $50-75 \%$ reduction of tan spot disease in wheat. However, wheat cultivars differed significantly in lesion lengths, lesion type (necrosis and/or chlorosis) in response to pathogen isolates, and in disease reaction on a $0-5$ scale (Evans et al., 1999; Lamari and Bernier, 1989; Raymond et al., 1985). Resistance in wheat cultivars to tan spot is complex; resistance to tan spot necrosis is governed by single recessive gene while resistance to chlorosis is governed by 
a single dominant gene (Anderson et al., 1999; Faris et al., 1996; Lamari and Bernier, 1991; Singh and Hughes, 2005; Stock et al., 1996). However, researchers also reported resistance to chlorosis is governed by a recessive gene (Friesen and Faris, 2004; Strelkov et al., 1999). Researchers also have reported quantitative resistance in wheat to tan spot (Elias et al., 1989; Faris et al., 1997; Hosford et al., 1988; Naglie at al., 1982). In quantitative genetics, where host resistance is controlled by minor genes, a greater degree of isolate-cultivar specificity may be detected by isolates representing many races (Van der Plank, 1982). However, when working with isolates from a single race, a low to moderate isolate-cultivar specificity has also been reported (Allingham and Jackson, 1981; Eyal et al., 1973; Rosielle and Boyd, 1985). In wheat- $P$. tritici-repentis pathosystem, isolate-cultivar specificity has also been reported (da Luz and Hosford, 1980; Krupinsky, 1982; Misra and Singh, 1972). Thus, Schilder and Bergstrom (1990) suggested that isolate-cultivar specificity based on quantitative difference in disease expression should also be considered in determining wheat resistance to tan spot.

To develop wheat varieties resistant to tan spot, evaluation of wheat lines to tan spot is critical. Such evaluation is facilitated if testing can be conducted in the greenhouse where large number of lines and plants can be consistently and reliably infected by $P$. tritici-repentis and if the reaction observed in the greenhouse evaluation consistently and accurately indicates field reaction to tan spot. Carson (1987) suggested the use of highly virulent isolates in resistance screening because highly virulent isolates maximize genetic variance of cultivars in disease reaction. In the $P$. tritici-repentis-wheat pathosystem, Schilder and Bergstrom (1990) also found a positive linear relationship between the mean virulence in isolates and variance in resistance in cultivars. Hence, the use of highly virulent isolates to detect variability of resistance in the host would be most effective. The objective of this study was to determine if there is any specificity between isolates of $P$. tritici-repentis collected in Oklahoma and hard red winter wheat cultivars developed in the southern Great Plains of the United States, and also to identify isolates for use in resistance screening to tan spot. Resistance to wheat cultivars to isolates also was determined.

\section{Materials and Methods}

Fungal isolates and wheat cultivars. Twelve isolates of $P$. tritici-repentis were collected from wheat fields in several counties in Oklahoma (Table 1). Isolates OKA1, OKA2, OKD1, OKD2, and OKD5 were collected in 1983; isolate RBB6 was collected in 1996; isolates Cherokee, Guymon, OK-06-01 and OK-06-03 were collected in 2006, and isolates Atoka and Kiowa were collected in 2007. Isolates were stored in liquid nitrogen for long term storage. Isolates were grown on CV8 media (Hunger and Brown, 1987). To confirm the isolates as $P$. tritici-repentis, DNA was extracted from each isolate by a salt extraction method (Aljanabi and Martinez, 1997). The nuclear internal transcribed spacer (ITS) region (ITS1-5.8S rDNA-ITS2) of each isolate was amplified by polymerase chain reaction (White et al., 1990) and was sequenced at the Oklahoma State University Core Facility. The sequences were compared in the NCBI database (http://www.ncbi.nih.gov) using the Basic Local Alignment Search Tool (BLAST). All isolates were determined as race 1 depending on the necrosis and/or chlorosis reactions on wheat differential lines (Andrie et al., 2007).

Table 1. Twelve isolates of tan spot fungus Pyrenophora tritici-repentis collected from several counties in Oklahoma and 11 cultivars of winter wheat included in the study

\begin{tabular}{lllll}
\hline Isolates & Collection year & Initial propagule & County & Wheat cultivars \\
\hline OKA1 & 1983 & Ascospore & Garfield & Chisholm \\
OKA2 & 1983 & Ascospore & Garfield & Deliver \\
OKD1 & 1983 & Ascospore & Blaine & Duster \\
OKD2 & 1983 & Ascospore & Blaine & Jagger \\
OKD5 & 1983 & Ascospore & Blaine & Karl 92 \\
RBB6 & 1996 & Ascospore & Kay & OK Bullet \\
Guymon & 2006 & Conidia & Texas & Okfield \\
Cherokee & 2006 & Conidia & Cherokee & OK Rising \\
OK-06-1 & 2006 & Ascospore & Payne & Pete \\
OK-06-3 & 2006 & Ascospore & Payne & TAM 105 \\
Atoka & 2007 & Conidia & Atoka & Triumph 64 \\
Kiowa & 2007 & Conidia & Pittsburg & - \\
\hline
\end{tabular}


Resistance to tan spot was determined in 11 wheat cultivars to these isolates. Wheat cultivars included in this study were Chisholm, Duster, Karl 92, Jagger, OK Bullet, OKfield, OK Rising, Pete, Red Chief, TAM 105, and Triumph 64. The wheat cultivar Red Chief and TAM 105 were used as resistant and susceptible checks, respectively (Table 1).

Fungal inoculum preparation. Twelve isolates of $P$. tritici-repentis were maintained on potato dextrose agar (200 g potato, dextrose $20 \mathrm{~g}$, agar $15 \mathrm{~g}$ in 11 ) at $4^{\circ} \mathrm{C}$ during the period of study. Conidia were produced from each isolate following the procedure of Raymond et al. (1985). A 5-mm diameter mycelial plug, excised with a sterile cork borer from the edge of an actively growing isolate, was placed on clarified V8 juice agar (CV8) (150 ml V8 juice, $3 \mathrm{~g} \mathrm{CaCO}_{3}$, $15 \mathrm{~g}$ agar, $850 \mathrm{ml}$ water) in a $90 \mathrm{~cm}$ petri plate. V8 juice was clarified by centrifugation at 7,500 rpm for $5 \mathrm{~min}$. After keeping in an incubator (Percival, Boone, IA, USA) at $23^{\circ} \mathrm{C}$ in the dark for 5 days, about 10 drops of sterile water was added and mycelia were matted down using a sterile bent glass rod. Plates were then kept in an incubator and exposed to cool-white fluorescent lighting $(40 \mathrm{~W}, 30 / \mu \mathrm{Es} /$ $\mathrm{m})$ for $12 \mathrm{~h}$ at $23^{\circ} \mathrm{C}$ to produce conidiophores, followed by $12 \mathrm{~h}$ dark at $16^{\circ} \mathrm{C}$ to induce conidia production. Conidia were collected in a beaker by washing with a stream of sterile water. Conidia were adjusted to 2,000 per $\mathrm{ml}$ of suspension before inoculation.

Wheat seedlings. Seeds of each cultivar were sown in 6 in. $\times 1.5$ in. diameter plastic cones containing a commercial 'Ready-Earth' soil (Sun Gro, Bellevue, WA, USA). Plants were raised in a growth chamber at $21{ }^{\circ} \mathrm{C}$ with a $14 \mathrm{~h}$ photoperiod $(550 / \mu \mathrm{Em} / \mathrm{s})$.

Inoculation and disease rating. When three leaves were fully expanded, wheat seedlings were inoculated using an atomizer (DeVilbiss Co., Sommerset, PA, USA) with a conidial suspension $(2,000$ conidia per $\mathrm{ml})$ of each isolate until incipient run-off. Isolates (main plot) and cultivars (sub plot) were arranged in a split-plot randomized complete block design experiment with four replications (10 plants per replication). About $1 \mathrm{~h}$ after inoculation, when conidia adhered to dried leaves, seedlings were placed in a mist chamber that provided near $100 \%$ relative humidity for 48 $\mathrm{h}$. Plants were then placed in a greenhouse at $21-23^{\circ} \mathrm{C}$. One week after inoculation, 2nd and 3rd leaves from the bottom were collected and scanned (EPSON 1650) to determine percent leaf area infection (LAI) using ASSESS software (Lamari, 2008). As leaf position affects tan spot severity (Cox and Hosford, 1987), only the 2nd and 3rd leaves were rated. All inoculations and disease rating experiments were repeated twice.

Data analysis. All analyses were performed using SAS 9.4 statistical software (SAS Institute, Cary, NC, USA). In the isolate $\times$ cultivar interaction study, untransformed data were analyzed. Isolate, cultivar, and their interaction were considered as fixed effect. Experiment, replication nested within experiment, and interactions involving experiment and replication were considered as random effect. Analysis of variance was carried out using the MIXED procedure, and treatment means were separated using the pairwise option (PDIFF) at 5\% level of probability. Similarity among 12 isolates in virulence on 11 cultivars was determined by CLUSTER procedure of SAS using centroid method. In centroid method the distance between two clusters is defined as the squared Euclidian distance between their centroids or means. Similarity of 11 cultivars in disease reaction (percent LAI) to 12 isolates also was determined. To determine the relationship between virulence of isolates and diseases reaction in cultivars, the variances of 11 wheat cultivars were plotted against the mean of virulence of each isolate, and a regression was performed. Similarly, variances of 12 isolates were plotted against mean disease reaction of each cultivar, and a regression analysis was performed (Schilder and Bergstrom, 1990).

\section{Results}

Variability in isolate virulence and cultivar response. Analysis of variance of percent LAI revealed that both isolates $(F=13.3, P<0.01)$ and cultivars $(F=247.6, P<$ $0.01)$ differed significantly in producing tan spot disease. A significant interaction $(F=7.6, P<0.01)$ between cultivar and isolate was also detected, thus, the interaction effects were separated by analyzing the simple effects of isolates and cultivars (Table 2). All isolates were pathogenic to wheat cultivars in the experiments, however, difference in isolate virulence in terms of LAI was observed. Mean percent LAI for isolates across all cultivars ranged from $9.0 \%$ to $20.9 \%$ (Table 2). Isolate Kiowa was the most virulent (LAI $20.9 \%$ ) followed by isolates OKD2, Cherokee, OKD5, OKA1, OKD1, RBB6, OKA2, OK-06-3, OK-061 , and Guymon. Isolate Atoka was the least virulent (LAI $9.0 \%$ ) isolate on the 11 wheat cultivars.

Cultivar Pete exhibited the highest resistance (LAI 4.4\%). The highest amount of disease was observed on the susceptible check TAM 105 (LAI 48.8\%) across all 12 isolates, which was followed by Chisholm (LAI 25.9\%), Duster (LAI 19.5\%), and Triumph 64 (LAI 12.6\%). Cultivars OK 


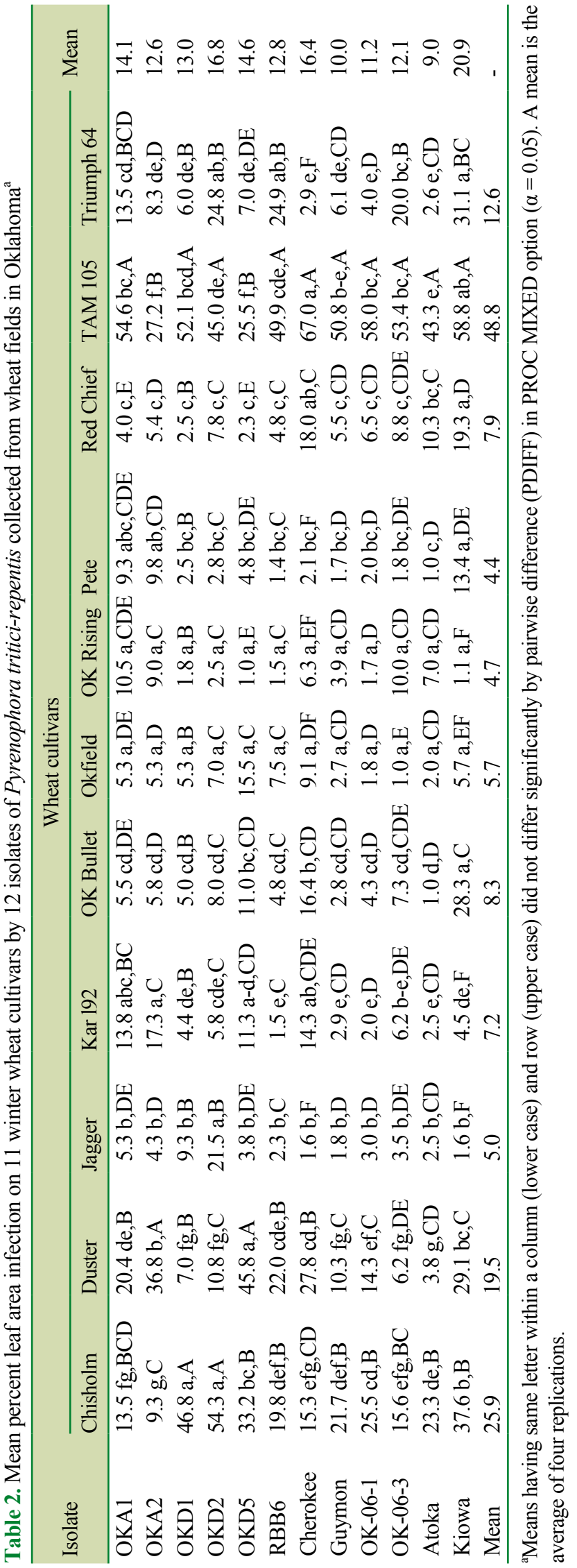

Rising, Jagger, Okfield, Kar192, and OK Bullet produced less disease which was similar to the resistant check Red Chief (Table 2).

Similarity in isolate virulence and cultivar response. Cluster analysis revealed that isolates divided into four groups based on their virulence on the 11 wheat cultivars. Isolates OKA1, OKD5, OKA2, OKD1, RBB6, OK-06-3, and OK-06-1 were in group 1, isolates Guymon and Atoka were in group 2, isolates OKD2 and Cherokee were in group 3, and Kiowa alone was in group 4 (Fig. 1). Based on disease reaction to the 12 isolates, cluster analysis revealed cultivars Chisholm and Duster were moderately susceptible and exhibited similarity in a group, while resistant cultivars Jagger, OK Rising, Pete, and Okfield were similar in a group, Karl 92, OK Bullet and the resistant check Red Chief were moderately resistant in a group, and Triumph 64 was susceptible in a group. As expected, highest disease appeared on the susceptible cultivar TAM 105 following inoculation to 12 isolates which formed a group alone (Fig.

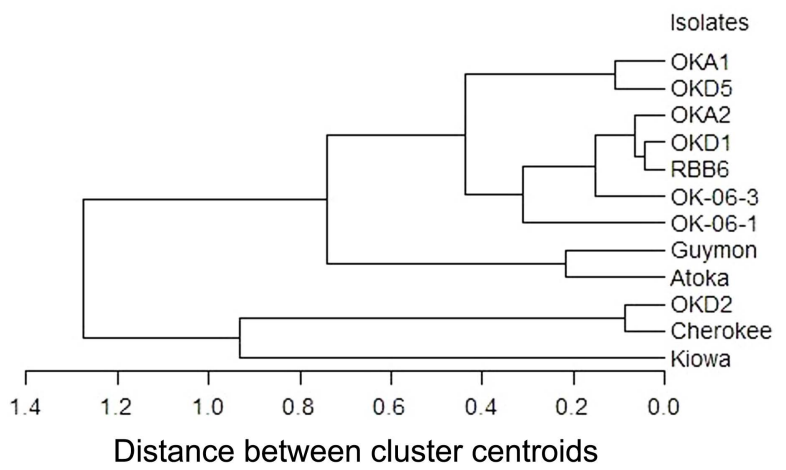

Fig. 1. Dendrogram showing similarity and clustering of 12 isolates of Pyrenophora tritici-repentis based on their virulence (percent leaf area infection) on 11 wheat cultivars.

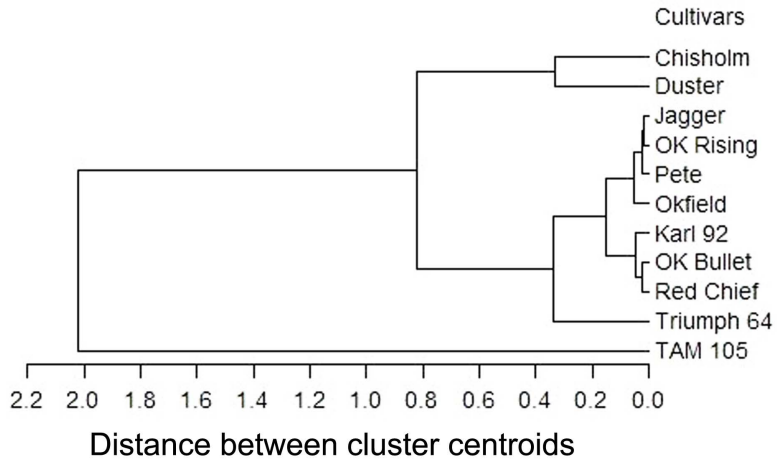

Fig. 2. Dendrogram showing similarity and clustering of 11 wheat cultivars based on their resistance (percent leaf area infection) to 12 isolates of Pyrenophora tritici-repentis. 


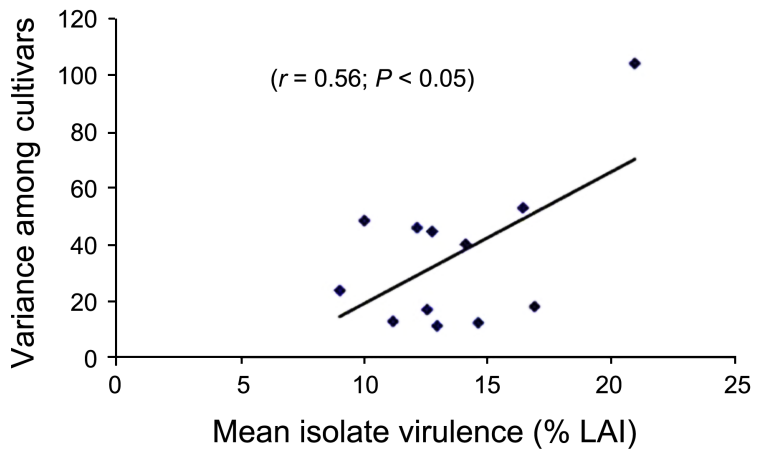

Fig. 3. Relationship between the mean virulence of 12 isolates of Pyrenophora tritici-repentis and variance in disease reaction among 11 wheat cultivars. LAI, leaf area infection.

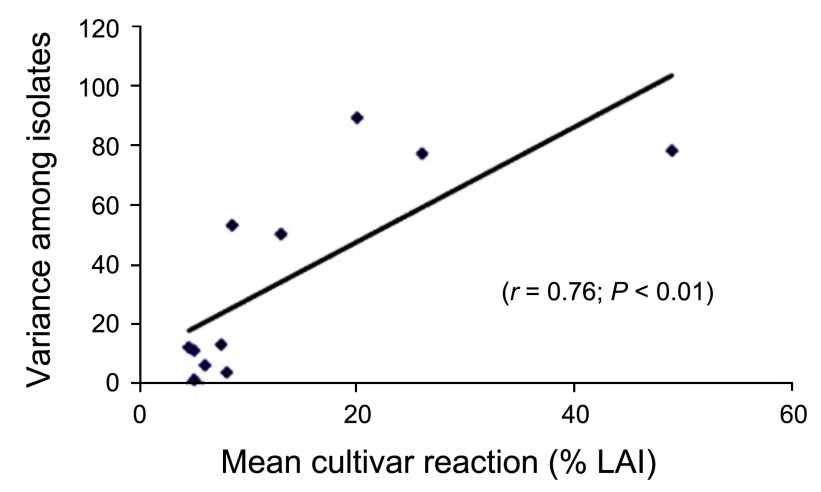

Fig. 4. Relationship between the mean disease reaction of 11 wheat cultivars and the variance in virulence among 12 isolates of Pyrenophora tritici-repentis.

\section{2).}

Relationship between isolate virulence and cultivar response. The variance in disease reaction among the wheat cultivars was positively correlated $(r=0.56, P<0.05)$ with mean isolate virulence (Fig. 3), and similarly, a positive correlation $(r=0.76, P<0.01)$ also was observed between the variance of isolate virulence and mean disease reaction of wheat cultivars (Fig. 4). Thus, the susceptible cultivars were able to differentiate virulence in isolates better than the resistant cultivars. Similarly, more virulent isolates were able to detect variability in cultivar response by producing disease better than less virulent isolates.

\section{Discussion}

In this study, 12 isolates of $P$. tritici-repentis exhibited a range of virulence on 11 wheat cultivars. For example, isolate Cherokee produced severe disease on the susceptible cultivar TAM 105 while causing lower severity on cultivar
Chisholm. Similarly, isolate Kiowa produced severe disease on the susceptible check TAM 105 but significantly less severe disease on cultivar Duster. However, both isolates OKD1 and OKD2 produced severe disease on cultivar Chisholm and the susceptible check TAM 105, but significantly less severe symptoms on other cultivars. This type of virulence variation by $P$. tritici-repentis and other fungal isolates across cultivars have been reported by other researchers (da Luz and Hosford, 1980; Krupinsky, 1992; Rufty et al., 1981) which are consistent with results in our study.

Since there is such a range of virulence among $P$. triticirepentis isolates, the use of lowly virulent isolates to screen for reaction to tan spot would not be as beneficial as using highly virulent isolates because lowly virulent isolates cannot differentiate disease reaction (LAI) in cultivars as compared to highly virulent isolates (Krupinsky, 1992). Thus, less virulent isolates should be excluded from isolate $\mathrm{x}$ cultivar interaction studies and several isolates representing a range of greater virulence should be used in screening wheat cultivars (Schilder and Bergstrom, 1990). Carson (1987) also suggested the use of highly virulent isolates of $P$. tritici-repentis to inoculate diverse genotypes of wheat for resistance to tan spot. In this study, we also found a general trend that an increased level of virulence in the isolate was able to detect increased level of variability in disease reaction in wheat cultivars (Fig. 3). Interestingly, few isolates such as OKA2, OKD1, OKD2, OKD3, and OK-06-1 exhibited a range of virulence $(11.2 \%$ to $16.8 \%$ LAI) but were not able to detect variability in cultivars disease reaction (Fig. 3). This could be due to isolate-cultivar specificity; however, the specificity should be less obvious in quantitative a host-pathogen interaction such as the wheat:tan spot pathosystem where there would always be some disease as compared to high isolate-cultivar specificity in a qualitative host-pathogen interaction such as the wheat:leaf rust pathosystem where there would be either no disease (hypersensitive reaction) or total damage of the crop (da Luz and Hosford, 1980; Schilder and Bergstrom, 1990). As isolates may show some level of specificity, selection of isolates should be carefully done in routine inoculation for resistance screening, and in this case, isolates which exhibited isolate-cultivar specificity should be discarded from cultivar resistance screening programs. Similarly, an increased level of susceptibility in cultivars was able to detect more variability in virulence in fungal isolates (Fig. 4), thus, inclusion of a susceptible checks is obvious.

A significant interaction between isolates and cultivars was observed. A significant interaction between isolates 
of $P$. tritici-repentis and wheat cultivars was also observed by other researchers (Krupinsky, 1992; Sah and Fehrmann, 1992; Schilder and Bergstrom, 1990). A significant interaction indicates specificity in host-pathogen interaction where a number of isolates are tested on several cultivars in all possible combination (Van der Plank, 1982). The isolate $\times$ cultivar interaction may also be influenced by environmental variations such as temperature, humidity, etc. (Jenns and Leonard, 1985; Kulkarni and Chopra, 1982). However, in this study the influence of environment should be negligible as the experiments were conducted under controlled conditions. An interaction might also be significant if isolates from different races are included in the study (Van der Plank, 1982). However, in this study all the isolates used in inoculation were race 1 , which is the predominant race present in Oklahoma (Ali and Francl, 2003; Kader, 2010). Another possible explanation for an interaction might be that untransformed data were analyzed. Typically this kind of experiment produces high variance and data transformation typically is not useful (Sah and Fehrmann, 1992; Schilder and Bergstrom, 1990).

Although only 12 isolates were included in the study, isolates revealed a range of variability in virulence phenotype. Cluster analysis revealed a maximum distance of 1.3 between cluster centroids (Fig. 1) in isolate virulence, which is an indication that isolates did not vary widely. Thus, the physiological specialization or the specificity between isolates and cultivars would be low to moderate. This finding is in agreement to other research with the wheat:tan spot pathosystem where a maximum distance of 1.4 between cluster centroids was revealed among the isolates that exhibited low to moderate specialization (Schilder and Bergstrom, 1990). In necrotrophic pathosystems such as wheat:tan spot, which follow a toxin-based gene-forgene action, the susceptibility in wheat and virulence in pathogen are governed by dominant genes and their interaction triggers a compatible (susceptible) phenotype (Strelkov and Lamari, 2003). Thus, as the resistance is incomplete and there would always be some level of infection. In contrast, in biotrophic pathosystems such as wheat:leaf rust, the genetic control of disease resistance is opposite. It follows a gene-for-gene action where wheat resistance to leaf rust and avirulence in pathogen are governed by dominant genes, and their genetic interaction triggers an incompatible (resistant) phenotype (Robinson, 1976). Thus, the resistance is complete, i.e., the resistance is exhibited by hypersensitive reaction or apparently no disease. Thus, in the wheat:tan spot pathosystem, adaptation of isolate(s) to a particular cultivar or loss of resistance in cultivars would not occur rapidly (Schilder and Bergstrom, 1990). Cluster analysis revealed wheat cultivars exhibited similarity in disease reaction to 12 isolates which was also reported by others (Schilder and Bergstrom, 1990). Wheat cultivars exhibiting resistance to isolates in this study should be stable in the field. Hence, it is expected the resistance found in OK Rising, Pete, Jagger, OK Bullet, and Okfield to tan spot likely will be durable resistance as isolates exhibiting a range of virulence were used in this study.

Cultivar resistance with these isolates was not determined in the field, however, isolate virulence or wheat resistance may be affected by different environmental conditions. In this experiment, testing of isolate virulence was conducted in the greenhouse because it was convenient and similar results to field study can be achieved. Evans et al. (1999) observed a high correlation $(r=0.75-0.93, P<$ 0.05 ) between greenhouse and field testing in identifying wheat resistant to tan spot. A correlation of 0.91 between greenhouse and field studies of wheat cultivars reactions to tan spot was also reported by other researchers (Raymond et al., 1985). Hence, use of multiple virulent isolates to test the reaction of cultivars and wheat lines in the greenhouse is quick, cost-effective and reliable.

The use of highly virulent isolates to screen for reaction to tan spot is desirable because a mixture of highly virulent isolates enhances detection of cultivars or breeder lines with a resistant response to tan spot. This study reveals that variability exists in the virulence of $P$. tritici-repentis isolates and in wheat cultivar resistance to tan spot, and demonstrates the value of identifying virulent isolates and susceptible cultivars for use in studies related to tan spot including testing for resistance to this disease.

\section{Conflicts of Interest}

No potential conflict of interest relevant to this article was reported.

\section{Acknowledgments}

Funding by the Oklahoma Agricultural Experimental Station and the Oklahoma Wheat Research Foundation is greatly acknowledged. We thank C. Siegerist for technical assistance.

\section{References}

Ali, S. and Francl, L. J. 2003. Population race structure of $P y$ renophora tritici-repentis prevalent on wheat and noncereal grasses in the Great Plains. Plant Dis. 87:418-422.

Allingham, E. A. and Jackson, L. F. 1981. Variation in pathoge- 
nicity, virulence, and aggressiveness of Septoria nodorum in Florida. Phytopathology 71:1080-1085.

Aljanabi, S. M. and Martinez, I. 1997. Universal and rapid saltextraction of high quality genomic DNA for PCR-based techniques. Nucleic Acids Res. 25:4692-4693.

Anderson, J. A., Effertz, R. J., Faris, J. D., Francl, L. J., Meinhardt, S. W. and Gill, B. S. 1999. Genetic analysis of sensitivity to a Pyrenophora tritici-repentis necrosis-inducing toxin in durum and common wheat. Phytopathology 89:293-297.

Andrie, R. M., Pandelova, I. and Ciuffetti, L. M. 2007. A Combination of phenotypic and genotypic characterization strengthens Pyrenophora tritici-repentis race identification. Phytopathology 97:694-701.

Bockus, W. W., Bowden, R. L., Hunger, R. M., Morrill, W. L., Murray, T. D. and Smiley, R. W. 2010. Compendium of wheat diseases and pests. 3rd ed. APS Press, St. Paul, MN, USA. 171 pp.

Carson, M. L. 1987. Assessment of six models of host-pathogen interaction in horizontal pathosystems. Phytopathology 77:241-246.

Cox, D. J. and Hosford, R. M. 1987. Resistant winter wheats compared at differing growth stages and leaf positions for tan spot severity. Plant Dis. 71:883-886.

da Luz, W. C. and Hosford, R. M. 1980. Twelve Pyrenophora trichostoma races for virulence to wheat in the Central Plains of North America. Phytopathology 70:1193-1196.

Elias, E., Cantrell, R. G. and Hosford, R. M. 1989. Heritability of resistance to tan spot in durum wheat and its association with other agronomic traits. Crop Sci. 29:299-304.

Evans, C. K., Hunger, R. M. and Siegerist, W. C. 1999. Comparison of greenhouse and field testing to identify wheat resistant to tan spot. Plant Dis. 83:269-273.

Eyal, Z., Amiri, Z. and Wahl, I. 1973. Physiologic specialization of Septoria tritici. Phytopathology 63:1087-1091.

Faris, J. D., Anderson, J. A., Francl, L. J. and Jordahl, J. G. 1996. Chromosomal location of a gene conditioning insensitivity in wheat to a necrosis-inducing culture filtrate from Pyrenophora tritici-repentis. Phytopathology 86:459-463.

Faris, J. D., Anderson, J. A., Francl, L. J. and Jordhal, J. G. 1997. RFLP mapping of resistance to chlorosis induction by Pyrenophora tritici-repentis in wheat. Theor. Appl. Genet. 94:98103.

Francl, L. J., Krupinsky, J. M. and McMullen, M. P. 1992. Advances in tan spot research. In: Proceedings of the Second International Tan Spot Workshop, eds. by L. J. Francl, J. M. Krupinsky and M. P. McMullen, p. 142. North Dakota State University, Fargo, ND, USA.

Friesen, T. L. and Faris, J. D. 2004. Molecular mapping of resistance to Pyrenophora tritici-repentis race 5 and sensitivity to Ptr ToxB in wheat. Theor. Appl. Genet. 109:464-471.

Hosford, R. M. 1988. Wheat leaf spot diseases. Annu. Wheat Newsl. 34:150-151.

Hunger, R. M. and Brown, D. A. 1987. Colony color, growth, sporulation, fungicide sensitivity, and pathogenicity of Pyre- nophora tritici-repentis. Plant Dis. 71:907-910.

Jenns, A. E. and Leonard, K. J. 1985. Reliability of statistical analyses for estimating relative specificity in quantitative resistance in a model host-pathogen system. Theor. Appl. Genet. 69:503-513.

Kader, K. A. 2010. Fitness, virulence and genetic variability of Pyrenophora tritici-repentis isolates casing tan spot of wheat in Oklahoma. Ph.D. thesis. Oklahoma State University, Stillwater, OK, USA.

Krupinsky, J. M. 1982. Observations on the host range of isolates of Pyrenophora trichostoma. Can. J. Plant Pathol. 4:42-46.

Krupinsky, J. M. 1992. Aggressiveness of Pyrenophora triticirepentis isolated from grass and barley hosts. Plant Dis. 76:783-789.

Kulkarni, R. N. and Chopra, V. L. 1982. Environment as the cause of differential interaction between host cultivars and pathogenic races. Phytopathology 72:1384.

Lamari, L. 2008. Assess 2.0 image analysis software for plant disease quantification. American Phytopathological Society, St. Paul, MN, USA. 125 pp.

Lamari, L. and Bernier, C. C. 1989. Virulence of isolates of Pyrenophora tritici-repentis on 11 wheat cultivars and cytology of the differential host reactions. Can. J. Plant Pathol. 11:284290.

Lamari, L. and Bernier, C. C. 1991. Genetics of tan necrosis and extensive chlorosis in tan spot of wheat caused by Pyrenophora tritici-repentis. Phytopathology 81:1092-1095.

Misra, A. P. and Singh, R. A. 1972. Pathogenic differences amongst three isolates of Helminthosporium tritici-repentis and the performance of wheat varieties against them. Indian Phytopathol. 25:350-353.

Naglie, B. J., Frohberg, R. C. and Hosford, R. M. Jr. 1982. Inheritance of resistance to tan spot of wheat. In: Tan spot of wheat and related disease workshop, eds. by R. M. Hosford Jr., pp. 40-45. North Dakota State University, Fargo, ND, USA.

Odvody, G. N., Boosalis, M. G. and Watkins, J. E. 1982. Development of pseudothecia during progressive saprophytic colonization of wheat straw by Pyrenophora trichostoma. In: Tan spot of wheat and related disease workshop, eds. by R. M. Hosford Jr., pp. 33-35. North Dakota State University, Fargo, $\mathrm{ND}$, USA.

Raymond, P. J., Bockus, W. W. and Norman, B. L. 1985. Tan Spot of winter wheat: procedures to determine host response. Phytopathology 75:686-690.

Robinson, R. A. 1976. Plant pathosystems. Springer-Verlag, Berlin, Germany. 186 pp.

Rosielle, A. A. and Boyd, W. J. 1985. Genetics of host-pathogen interactions of the Septoria species of wheat. In: Septoria of Cereals: Proceedings of the Workshop, ed. by A. L. Scharen, pp. 9-12. United States Department of Agriculture, Washington, DC, USA.

Rufty, R. C., Hebert, T. T. and Murphy, C. F. 1981. Variation in virulence in isolates of Septoria nodorum. Phytopathology 71:593-596. 
Sah, D. N. and Fehrmann, H. 1992. Virulence patterns of geographically differing isolates of Pyrenophora tritici-repentis and sources of resistance in wheat. Plant Dis. 76:712-716.

Schilder, A. M. C. and Bergstrom, G. C. 1990. Variation in virulence within the population of Pyrenophora tritici-repentis in New York. Phytopathology 80:84-90.

Shabeer, A. and Bockus, W. W. 1988. Tan spot effects on yield and yield components relative to growth stage in winter wheat. Plant Dis. 72:599-602.

Singh, P. K. and Hughes, G. R. 2005. Genetic control of resistance to tan necrosis induced by Pyrenophora tritici-repentis, races 1 and 2, in spring and winter wheat genotypes. Phytopathology 95:172-177.

Singh, S., Bockus, W. W., Sharma, I. and Bowden, R. L. 2008. A novel source of resistance in wheat to Pyrenophora triticirepentis race 1. Plant Dis. 92:91-95.

Sone, J., Bockus, W. W. and Claassen, M. M. 1994. Gradients of tan spot of winter wheat from a small-area source of Pyrenophora tritici-repentis. Plant Dis. 78:622-627.
Stock, W. S., Brûlé-Babel, A. L. and Penner, G. A. 1996. A gene for resistance to a necrosis-inducing isolate of Pyrenophora tritici-repentis located on 5BL of Triticum aestivum cv. Chinese Spring. Genome 39:598-604.

Strelkov, S. E., Lamari, L. and Ballance, M. 1999. Characterization of a host-specific protein toxin (Ptr ToxB) from Pyrenophora tritici-repentis. Mol. Plant-Microbe Interact. 12:728732.

Strelkov, S. E. and Lamari, L. 2003. Host-parasite interactions in tan spot Pyrenophora tritici-repentis of wheat. Can. J. Plant Pathol. 25:339-349.

Van der Plank, J. E. 1982. Host-pathogen interaction in plant disease. Academic Press, New York, NY, USA. 207 pp.

White, T. J., Bruns, T., Lee, S. and Taylor, J. 1990. Amplification and direct sequencing of fungal ribosomal RNA genes for phylogenetics. In: PCR protocols: a guide to methods and applications, eds. by M. A. Innis, D. H. Gelfand, J. J. Sninsky and T. J. White, pp. 315-322. Academic Press, San Diego, CA, USA. 